\title{
Systematic Reviews and Meta-Analyses of the Incidence and Prevalence of Dementia and Its Commoner Neurodegenerative Causes
}

\author{
Nathalie Jetté, Colleen J. Maxwell, Kirsten M. Fiest, David B. Hogan
}

Keywords: Alzheimer's disease, dementia, degenerative diseases

doi:10.1017/cjn.2016.38

Can J Neurol Sci. 2016; 43: S1-S2

The National Population Health Study of Neurological Conditions (NPHSNC) was an ambitious program of research funded by the Government of Canada designed to improve our understanding of neurological conditions and their impact on Canadians., It consisted of three national surveys and 13 pan-Canadian research projects targeting 15 priority neurological conditions, including Alzheimer's disease (AD) and related dementias. One of the projects consisted of carefully performed systematic reviews (and, where possible, meta-analyses) of incidence and prevalence studies of these priority conditions. ${ }^{3}$

In this supplement, we report on the results of this work on dementia overall and for the more common underlying neurodegenerative causes (i.e., dementia due to $\mathrm{AD}$, dementia with Lewy bodies [DLB], frontotemporal dementia [FTD]). Table 1 provides a summary of the key findings that are elaborated on in the papers in this supplement. Table 2 provides definitions of the epidemiological estimates for prevalence and incidence reported in these papers.

Accurate information on the epidemiology of dementia is important for planning services to deal with the needs of those suffering from the condition as well as those of their family and caregivers. In projecting future demand, we must determine if incidence and/or prevalence is changing or remaining much as before in the population we serve. Otherwise, there is a risk of either under- or overestimating the resources required if our projections are based on dated information or figures imported from other nations. Finding evidence of true variation over time or across regions suggests that future rates are potentially changeable. Interventions directed at modifiable risk factors in future cohorts could lead to significant delays in onset if not outright prevention of age-related dementia. The need for accurate and timely information underscores the necessity of continuing to do epidemiological studies of these conditions.
As noted in the individual papers, there are a number of methodological issues with the incidence and prevalence studies done to date that detract from our ability to obtain accurate estimates that, among other things, can be used to look for variability across time and regions. While some of these methodological challenges are unique to the specific conditions reviewed, a number are common to all dementias and other neurological conditions. ${ }^{3}$ Future studies must use validated diagnostic criteria and approaches to case ascertainment. One particular challenge will be determining how to implement new diagnostic criteria in a manner that ensures that we have data comparable to those from studies using older ones. Unless driven by a particular study design requirement, investigators should target similarly aged populations of the two sexes, collect standardized data and report results in a consistent manner. Use of the recently published standards of reporting of neurological disorders (STROND) checklist, a guideline for incidence and prevalence studies of these conditions, should enhance the quality of future publications. ${ }^{4}$

Notwithstanding these limitations, this supplement summarizes our current understanding of the epidemiology of $\mathrm{AD}$ and related disorders. Our work was guided by recommended methodology. ${ }^{5}$ Literature searches identified a total of 16,066 citations, with 707 papers selected for full-text reviews conducted by 11 reviewers using a standardized approach. Abstracted data were analyzed, with the findings discussed internally as to what they indicated before conclusions were reached. On behalf of our study team, we are delighted to present the results.

\section{ACKNOWLEDGMENTS}

Our study is part of the National Population Health Study of Neurological Conditions. We acknowledge the membership of Neurological Health Charities Canada and the Public Health Agency

From the Hotchkiss Brain Institute, University of Calgary, Calgary, Alberta, Canada (NJ, KMF, DBH); Department of Community Health Sciences, University of Calgary, Calgary,

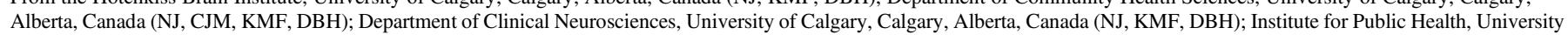

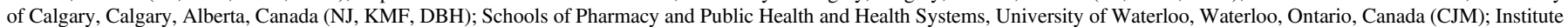
for Clinical Evaluative Sciences, Toronto, Ontario, Canada (CJM); Brenda Stafford Chair in Geriatric Medicine, University of Calgary, Calgary, Alberta, Canada (DBH).

Received January 5, 2016. Date of Acceptance February 23, 2016.

Correspondence to: Nathalie Jetté, Foothills Medical Center, Department of Clinical Neurosciences, 1403-29th Street NW, Calgary, Alberta T2N 4N1, Canada. Email: Nathalie. jette@albertahealthservices.ca 
Table 1: Summary of select key findings from the dementia systematic reviews

\begin{tabular}{|c|c|}
\hline Dementia & Individuals $60+$ residing in the community \\
\hline & $\begin{array}{l}\text { - } \text { Pooled point prevalence } 48.62\left(\mathrm{CI}_{95 \%}: 41.98-56.32\right) \text { per } 1000 \text { persons } \\
\text { - } \text { Pooled annual period prevalence } 69.07\left(\mathrm{CI}_{95 \%}: 52.36-91.11\right) \text { per } 1000 \text { persons } \\
\text { - } \text { Pooled incidence rate } 17.18\left(\mathrm{CI}_{95 \%}: 13.90-21.23\right) \text { per } 1000 \text { person-years } \\
\text { - } \text { Pooled annual incidence proportion } 52.85\left(\mathrm{CI}_{95 \%}: 33.08-84.42\right) \text { per } 1000 \text { persons } \\
\text { - Increasing age associated with higher estimates } \\
\text { - } \text { Annual period prevalence higher in North America and higher in institutional settings }\end{array}$ \\
\hline \multirow[t]{2}{*}{ Dementia due to Alzheimer's disease } & Individuals $60+$ residing in the community \\
\hline & $\begin{array}{l}\text { - Pooled point prevalence } 40.19\left(\mathrm{CI}_{95 \%}: 29.06-55.59\right) \text { per } 1000 \text { persons } \\
\text { - } \quad \text { Pooled annual period prevalence } 30.40\left(\mathrm{CI}_{95 \%}: 15.64-59.12\right) \text { per } 1000 \text { persons } \\
\text { - } \text { Pooled incidence rate } 15.83\left(\mathrm{CI}_{95 \%}: 12.94-19.37\right) \text { per } 1000 \text { person-years } \\
\text { - } \quad \text { Pooled annual incidence proportion } 34.14\left(\mathrm{CI}_{95 \%}: 16.44-70.92\right) \text { per } 1000 \text { persons } \\
\text { - Estimates vary significantly with age, diagnostic criteria and location }\end{array}$ \\
\hline \multirow[t]{2}{*}{ Dementia with Lewy bodies } & Individuals of all ages residing in the community or institutions \\
\hline & $\begin{array}{l}\text { - Point and period prevalence estimates range from } 0.02 \text { to } 63.55 \text { per } 1000 \text { persons } \\
\text { - Incidence rates range from } 0.50 \text { to } 1.60 \text { per } 1000 \text { person-years } \\
\text { - Increasing prevalence with increasing age } \\
\text { - Accounts for about } 5 \% \text { of dementia cases }\end{array}$ \\
\hline \multirow[t]{2}{*}{ Frontotemporal dementia } & Individuals of all ages residing in the community or institutions \\
\hline & $\begin{array}{l}\text { - Period prevalence estimates range from } 0.16 \text { to } 31.04 \text { per } 1000 \text { persons } \\
\text { - Incidence rates ranged from } 0.00 \text { to } 0.33 \text { per } 1000 \text { person-years } \\
\text { - Accounts for about } 3 \% \text { of dementia cases in studies including subjects } 65+\text { and about } 10 \% \text { among studies restricted to those less than } 65\end{array}$ \\
\hline
\end{tabular}

Table 2: Epidemiological terms defined

\begin{tabular}{|c|c|}
\hline Term & Definition $^{6}$ \\
\hline Point prevalence & Proportion of individuals diagnosed with a condition (e.g., dementia) at a specified point in time (e.g., May 1, 2016). \\
\hline Period prevalence & Proportion of individuals diagnosed with a condition (e.g., dementia) during a specified period of time (e.g., between May 1 and August 30, 2016). \\
\hline Incidence proportion & $\begin{array}{l}\text { Number of instances a condition (e.g., dementia) is diagnosed during a specified period of time (note: time duration must be specified for the value to } \\
\text { be meaningful) expressed as the proportion of the population at risk for the condition (e.g., } 33 \text { per } 1000 \text { persons during the period of observation). }\end{array}$ \\
\hline Incidence rate & $\begin{array}{l}\text { Number of new cases diagnosed with a condition (e.g., dementia) over a defined period of time (e.g., a year) in a specified population who are at risk of } \\
\text { experiencing the event (e.g., } 33 \text { per } 1000 \text { person-years). }\end{array}$ \\
\hline
\end{tabular}

of Canada for their contribution to the success of this initiative. Funding for the study was provided by the Public Health Agency of Canada. The opinions expressed in this publication are those of the authors/researchers and do not necessarily reflect the official views of the Public Health Agency of Canada. The authors would like to acknowledge the unrestricted financial support provided by the Hotchkiss Brain Institute and the Brenda Strafford Foundation Chair in Geriatric Medicine for the publication of this supplement.

\section{Disclosures}

Nathalie Jetté has the following disclosures: Public Health Agency of Canada, Principal Investigator, research support; Canada Research Chair, Researcher, research support; Alberta Innovates Health Solutions, Researcher, research support.

David Hogan holds the Brenda Strafford Foundation Chair in Geriatric Medicine, though receives no salary support from this.

Kirsten Fiest and Colleen Maxwell do not have anything to disclose.

\section{REFERENCES}

1. Caesar-Chavannes CR, MacDonald S. National Population Health Study of Neurological Conditions in Canada. Chronic Dis Inj Can. 2013;33:188-91.

2. Bray GM, Strachan D, Tomlinson M, Bienek A, Pelletier C on behalf of multiple contributors including Hogan DB. Mapping connections: an understanding of neurological conditions in Canada. Ottawa: The Public Health Agency of Canada, Health Canada and The Canadian Institutes of Health Research; 2014.

3. Pringsheim T, Fiest K, Jetté N. The international incidence and prevalence of neurological conditions: how common are they? Neurology. 2014;83:1661-4.

4. Bennett DA, Brayne C, Feigin VL, Barker-Collo S, Brainin M, Davis D, et al. Development of the standards of reporting of neurological disorders (STROND) checklist: a guideline for the reporting of incidence and prevalence studies in neuroepidemiology. Neurology. 2015;85(9):821-8.

5. Moher D, Liberati A, Tetzlaff J, Altman DG, PRISMA Group. Preferred reporting items for systematic reviews and metaanalyses: the PRISMA statement. PLoS Med. 2009;6:e1000097.

6. Porta M (editor), Greenland S, Last JM (associate editors). A dictionary of epidemiology, 5th ed. Oxford: Oxford University Press; 2008. 